\title{
Biochemical studies on moringa oleifera seed oil
}

\begin{abstract}
The purpose of the present study was to examine the physico-chemical properties, fatty acids composition, unsaponifiable matter, tocopherols and phenolic content of Moringa oleifera seed oil from Al-Ahsa, Saudi Arabia. In addition, biological evaluation of this oil was determined. Moringa oil showed a better overall quality, its, acid, peroxide, iodine, saponification values. Sterol fraction was found rich in $\beta$-sitosterol (45.11), stigmasterol (19.20\%), campesterol (16.90\%) and $\Delta 5$-avenasterol $(10.00 \%)$. The major fatty acids were identified as oleic acid $(65.00 \%)$. These results strongly suggested in potential use Moringa oil as non- conventional seed crop for high quality oil.
\end{abstract}

Keywords: moringa oleifera, physico-chemical properties, fatty acids, biological evaluation
Volume 2 Issue 2 - 2016

\author{
Amany M Basuny, Maliha A Al-Marzouq \\ Food Science \& Nutrition Department, King Faisal University, \\ Saudi Arabia
}

Correspondence: Amany M Basuny, Food Science \& Nutrition Department, Faculty of Agricultural Science \& Foods, King Faisal University, Saudi Arabia, Email dramany_basuny@yahoo.com

Received: November 3, 2015 | Published: February 24, 2016

\section{Introduction}

Moringa oleifera lam. (M. olefera), a small deciduous tree, is the most widely naturalized species of Moringaceae family and is commonly known as the horseradish or drumstick tree. ${ }^{1}$ It is native in Asia Minor, Africa, the Indian subcontinent (Bangladesh, India \& Pakistan $),{ }^{2}$ and is also distributed in the Philippines, Cambodia, Central America, North and South America, and the Caribbean Islands. ${ }^{1}$ The tree ranges in height from 5 to $12 \mathrm{~m}$ and the fruits (pods) are around $50 \mathrm{~cm}$ long. When mature, the fruit of $M$. oleifera became and has $10-50$ seeds inside. Fully mature dry seeds are round or triangular in shape and the kernel is surrounded by a light woody shell with three papery wings. ${ }^{3}$ All parts of the Moringa tree-leaves, flowers fruits, and roots are edible and have long been consumed as vegetables ${ }^{4}$ and used to treat many diseases such as abdominal tumors, hysteria, scurvy, paralytic attacks, helmintic bladder, prostate troubles, sores and skin infections. ${ }^{5}$ The leaves are highly nutritious, which contain more vitamin A than carrots, more calcium than milk, more iron than spinach, more vitamin $\mathrm{C}$ than oranges and more potassium than bananas and more protein than milk and eggs. ${ }^{6}$ Moreover, leaves of Moringa species are rich in various phytochemicals like carotenoids, amino acids, sterols, glycosides, alkaloids, flavonoids, moringine, moringinine, phytoestrogens, caffeoylquinic acid and phenolic compounds. ${ }^{7}$ Fruits and seeds have been reported as a rich source of protein, essential elements $(\mathrm{Ca}, \mathrm{Mg}, \mathrm{K}$ and $\mathrm{Fe}$ ) and vitamins (A, C, and E). The oil extracted from its seeds (Known as ben or behen oil due to the high behenic acid content) has a $38-40 \%$ yield and can be used as a food, a cosmetic, and a lubricant. ${ }^{8}$ In African and some parts of Asia, Particularly India, the oil has been used for cooking purposes. $^{9}$ In recent years, considering the gap between demand and production of vegetable oils in many developing countries, ${ }^{9}$ research focusing on the use of unconventional oilseeds as a source of vegetable oils has become important. There are some reports on the composition and characteristics of M. oleifera seed oil varieties from different countries of origin eg: India, Kenya, Malawi, Malaysia, Pakistan, $, 3,7,10,11$ considering its prospect as an alternative vegetable oil source. The refined oil is clear, odorless and rancid-resistant. Seed biomass remaining after the oil extraction can be used as a fertilizer or flocculating agent for water purification. ${ }^{12}$ The oil extracted from $M$. oleifera seeds is regarded as having a good commercial interest due to its physical, chemical and pharmacological characteristics. ${ }^{13}$
The objectives of this study were to determine physico-chemical, fatty acid composition, unsaponifiable matter and bioactive components of oil extracted from the seeds of Moringa oleifera trees. In addition, biological evaluation of oil was evaluated.

\section{Materials and methods}

\section{Plant materials}

Moringa oleifera seeds (PKM1, variety) were procured from local market of Al-Ahsa, Saudi Arabia. The seeds were air-dried at room temperature $\left(25^{\circ} \mathrm{C}\right)$ for 1 week.

\section{Chemicals}

All chemicals used were of analytical or HPLC grade from Merck (Darmstadt, Germany) or Sigma Aldrich (St. Louis, Mo, USA). Standards of sterols, tocopherol and phenolic compounds were obtained from FlukaChemie (Buchs, Switzerland).

\section{Oil extraction}

The oil from the seeds was extracted with n-hexane using the method described by Tsakins et al. ${ }^{14}$

\section{Proximate analysis}

The methods of the AOAC (2012) were used for proximate analysis. Moring a flower sample (5grams) was used for determination of moisture content by weighing in crucible and drying in oven at $105^{\circ} \mathrm{C}$, until a constant weight was obtained. Determination of ash content was done by ashing at $550^{\circ} \mathrm{C}$ for $3 \mathrm{hr}$. The kjeldah method was used to determine the protein content. The crude fiber content of the samples was determined by digestion method and the fat was done by Soxhlet extraction method. All determinations were done in triplicate.

\section{Determination of the physico-chemical properties}

The extracted Moringa oil was analyzed immediately for refractive index, color, acid value, peroxide value, iodine number and saponification number as described in AOAC. ${ }^{15}$

\section{Oxidative stability}

The oxidative stability was estimated by measuring the oxidation induction time, on a Rancimat apparatus (Metrohm CH series 679). Air 
(20L/h was bubbled through the oil $(5.0 \mathrm{~g})$ heated at $100^{\circ} \mathrm{C} \pm 2^{\circ} \mathrm{C}$, with the volatile compounds being collected in water, and the increasing water conductivity continually measured. The time taken to reach the conductivity inflection was recorded. ${ }^{16}$

\section{Fatty acid composition}

Capillary gas chromatograph (HP 6890) was used for the qualitative and quantitative determinations of fatty acids of the oil and reported in relative area percentages. Fatty acids were transesterfied into their corresponding fatty acid methyl esters by shaking a solution of oil $(0.1 \mathrm{~g})$ in heptane $(2 \mathrm{ml})$ with solution methanolic potassium hydroxide $(0.2 \mathrm{ml}, 2 \mathrm{~N})$. The fatty acid methyl esters were identified using a gas chromatograph equipped with DB-23 (5\%-cyanopropyl-methyl poly siloxane) capillary column $(60 \mathrm{mx} 0.32 \mathrm{mmX} 0.25 \mu \mathrm{m}$ film thickness $)$ and flame ionization detector. Nitrogen flow rate was $0.6 \mathrm{ml} / \mathrm{min}$, hydrogen and air-flow rates were 45 and $450 \mathrm{ml} / \mathrm{min}$, respectively. The oven temperature was isothermally heated $195^{\circ} \mathrm{C}$. The injector and the detector temperatures were $230^{\circ} \mathrm{C}$ and $250^{\circ} \mathrm{C}$, respectively. Fatty acid methyl esters were identified by comparing their retention times with known fatty acid standard mixture. Peak areas were automatically computed by an integrator. All GC measurements for each oil sample were made in triplicate and the averages were reported.

\section{Identification of unsaponifiable matter}

The unsaponifiable matters of Moringa oil was analyzed by an Hp 5890 gas chromatograph equipped with FID detector and DB-5 capillary column $(30 \mathrm{~m}, 0.25 \mathrm{~mm}$ ( $5 \%$ phenyl)- $95 \%$ methyl polysiloxane, $0.25 \mu \mathrm{m}$ film thickness, $280^{\circ} \mathrm{C}$ temperature injector and $300^{\circ} \mathrm{C}$ temperature transfer line. The oven temperature was programmed as follows: initial temperature: $100^{\circ} \mathrm{C}$ for $2 \mathrm{~min}$, increase $10^{\circ} \mathrm{C} / \mathrm{min}$ up to $300^{\circ} \mathrm{C}$, and then hold for $20 \mathrm{~min}$. The carrier gas was $\mathrm{N}_{2}(2 \mathrm{ml} / \mathrm{min})$. The identification of the different compounds was performed by comparing of its relative retention times with those of authentic reference compounds.

\section{Determination of total phenolic content}

The levels of total polyphenols of fresh crude sidr juice (fruit and leaf) were determined according to the method of Gutfinger. ${ }^{17}$ Caffeic acid was served as a standard compound for the preparation of the calibration curve.

\section{Tocopherol analysis}

Tocopherol ( $\alpha, \beta$ and $\delta$ ) analysis was performed using an HPLC system consisting of a L-6000 Merck-Hitachi high pressure ppm connected to an L-4000Merk Hitachi UV detector (Hitachi Instruments Inc., Tokyo, Japan) set at $295 \mathrm{~nm}$. Tocopherol contents were identified by comparing the retention times with those of pure standards as described by others. ${ }^{718}$ AD-2500chromato Integrator (Merck, Darmstadt, Germany) was used for data acquisition and processing.

\section{Animals}

Twenty four day old male fisher rats were housed in individual cages and kept under controlled conditions of temperature and humidity with a light/dark cycle of $12-12 \mathrm{hr}$. Diets and water were offered ad libitum for 49days food consumption was monitored weekly.

\section{Biological evaluation}

For the biological evaluation, three types of diets were prepared: a standard one, containing corn oil (control group), and the test diets containing the Moringa oil and olive oil. The animals were divided randomly in the groups of eight rats each: corn oil, Moringa oil and olive oil. Diets (Table 1) were prepared according to $\mathrm{AOCA}^{15}$ and stored under refrigeration $\left(0-4^{\circ} \mathrm{C}\right)$ for not more than seven days.

\section{Biochemical determinations}

After 49days, the animals were fasted overnight and anesthetized with ether for blood removal through the orbital plexus. Total cholesterol, HDL-cholesterols, triglycerides, albumin, total proteins, hemoglobin, trnasaminases, alkaline phosphatase (ALP), urea and creatinine were determined using the commercial kits (Labtest, Lagoa Santa, MG, Brazil).

\section{Statistical analysis}

All experiments and measurements were carried out in triplicate, and the data were suggested to analysis of variance (ANOVA). Analysis of variance and regression analyses were performed according to the MStat $\mathrm{C}$ and Excel software. Significant differences between means were determined by Duncan's multiple range tests. $\mathrm{P}$ values less than 0.05 were considered statistically significant.

\section{Results and discussion}

The results of the proximate composition of Moringa seeds are shows in Table 1. The moisture content of the Moringa seed was $4.90 \%$. The Moringa seed had higher values in the ash, crude fiber and protein and carbohydrate contents. These values were higher than the values observed by Anwar et al. ${ }^{11}$ for Moring $a$ flour. The high protein content of these flour samples give an indication of their usefulness in human diet and as livestock feed. The Moringa seed had higher fat content of $45.00 \%$. The value was higher than the value $(42 \%)$ reported by Ogunsina et al. ${ }^{19}$

Table I Analysis of moringa oleifera seeds

\begin{tabular}{ll}
\hline Constituents (\%) & M. oleifera seeds \\
\hline Moisture & $4.90 \pm 0.55$ \\
Oil & $45.00 \pm 4.10$ \\
Protein & $7.10 \pm 0.65$ \\
Fiber & $5.30 \pm 0.61$ \\
Ash & $31.65 \pm 2.90$ \\
Carbohydrate & $10.95 \pm 1.15$
\end{tabular}

Values are mean $\pm S D$ calculated as percentage of dry weight for $M$. oleifera seeds, analyzed individually in triplicate.

Table 2 shows various physico-chemical characteristics of the extracted $M$. oleifera oil from Saudi Arabia. The values determined for iodine number $\left(69.01 \mathrm{gI} / 100 \mathrm{~g}\right.$ oil), refractive index at $25^{\circ} \mathrm{C}$ (1.4570), saponification values (183.20 $\mathrm{mgKOH} / \mathrm{g}$ oil). However, the color at yellow 35.00 (2.00Red) value. Color of the oils is mainly attributed to the presence of natural pigments which are extracted along with the oil during extraction and are effectively removed during the bleaching step of processing of oil. The value of acidity $(0.60 \%$ as oleic acid) was considerably lower than M. oleifera oil from India. ${ }^{20}$ Oils with lower values of acidity are more acceptable 
for edible applications. The peroxide value $\left(0.83\right.$ meq. $\mathrm{kg}^{-1}$ of oil $)$ which measure hydroperoxides of the oils, this value was lower than those of M. oleifera oils from Kenya, ${ }^{21}$ and India. ${ }^{20}$ The induction period (Rancimat: $20 \mathrm{~L} / \mathrm{h}, 100^{\circ} \mathrm{C} \pm 2^{\circ} \mathrm{C}$ ) is an important feature which describes the oxidative stability of oil and fats. ${ }^{4}$ The induction period of the investigated M. oleifera oil $(10.50 \mathrm{~h})$ was comparable with those M. oleifera oils reported from Sindh ${ }^{4}$ but significantly lower than from India ${ }^{20}$ and Pakistan. ${ }^{22}$

Table 2 Physico-chemical properties of Moringa oleifera oil

\begin{tabular}{ll}
\hline Properties & M. Oleifera oil \\
\hline Refractive index $\left(25^{\circ} \mathrm{C}\right)$ & $1.4570 \pm 0.001$ \\
Color (Red unit) & $2.00 \pm 0.33$ \\
Acidity (\% as oleic acid) & $0.60 \pm 0.09$ \\
Peroxide number (meq. $\mathrm{O}_{2} / \mathrm{kg}$ oil) & $0.83 \pm 0.13$ \\
Iodine number (gI/100g oil) & $69.01 \pm 5.30$ \\
Inductions period (hrs) & $10.50 \pm 1.00$ \\
\hline
\end{tabular}

Values are mean \pm SD for M. oleifera oil, analyzed individually in triplicate.

Phenolic compounds have been proved to be responsible for antioxidant activity on many vegetable seeds oils, it is mainly due to their redox properties, which can play an important role in absorbing and neutralizing free radicals, quenching singlet and triplet oxygen or decomposing peroxides. ${ }^{23}$ Total phenolic compounds in the M. oleifera seed oil was $(160.00 \mu \mathrm{g} / \mathrm{g})$. These values were well comparable to those reported in other Moringa species native to Kenya, Pakistan and Egypt.

The data for tocopherol analysis of the M. oleifera oil from Saudi Arabia are presented in Table 3. The levels of $\alpha, \gamma$ and $\delta$-tocopherol in the oil were $150.00,70.80$ and $55.50 \mu \mathrm{g} / \mathrm{g}$, respectively. The content of $\alpha$-tocopherol in the M. oleifera oil was in close agreement with the values reported for soybean, groundnut and palm oils. ${ }^{24}$ The contents of $\gamma$-tocopherol in the M. oleifera oil was slightly lower than those of $M$. oleifera oil from Malawi ${ }^{25}$ but considerably higher than those from India. ${ }^{20}$ The concentration of $\delta$-tocopherol was slightly lower than the values reported for $M$. oleifera oil from Kenya. ${ }^{21}$ Literature revealed that $\alpha$-isomer of tocopherol has greatest vitamin E potency, whereas, $\delta$-isomer of tocopherol has greater antioxidant efficacy than either $\gamma$-or $\alpha$-tocopherol. ${ }^{21,24}$

Table 3 Phenolic and tocopherol contents (ppm) of Moringa oleifera oil

\begin{tabular}{ll}
\hline Components & M. oleifera Oil \\
\hline Total phenolic compound & $160.00 \pm 8.90$ \\
$\alpha$-tocopherol & $150.00 \pm 7.50$ \\
$\gamma$-tocopherol & $70.80 \pm 4.10$ \\
$\delta$-tocopherol & $55.50 \pm 3.15$ \\
\hline
\end{tabular}

Values are mean $\pm \mathrm{SD}$ for M. oleifera oil, analyzed individually in triplicate.

The sterols profile of $M$. oleifera oil is shown in Table 4. The sterol fraction of M. oleifera oil from Saudi Arabia mainly consisted of $\beta$-sitosterol (45.11\%), stigmasterol (19.20\%), campesterol $(16.90 \%)$ and $\Delta^{5}$-avenasterol $(10.00 \%)$, together with small amounts of clerosterol, 24-methylene cholesterol, $\Delta^{7}$-campestanol, $\Delta^{7}$ avenasterol, stigmastanol and 28. isoavenasterol, cholesterol and brassicasterol. The contents of $\beta$-sitosterol, stigmasterol, campesterol and $\Delta^{5}$-avenasterolin the present analysis of $M$. oleifera oil were rather comparable with the values for M. Oleifera oil reported from Kenya and India. The sterol composition of the major constituents of the investigated $M$. oleifera oil generally varied to those of most of the conventional edible oils. ${ }^{24}$

Table 4 Sterol composition of Moringa oleifera oil

\begin{tabular}{lc}
\hline Sterol (\%) & M. oleifera Oil \\
\hline$\beta$-sitosterol & $45.11 \pm 3.11$ \\
Stigmasterol & $19.20 \pm 1.33$ \\
Campesterol & $16.90 \pm 0.91$ \\
$\Delta^{5}$-avensterol & $10.00 \pm 0.84$ \\
Clerosterol & $1.20 \pm 0.19$ \\
24-methylene cholesterol & $0.90 \pm 0.11$ \\
$\Delta^{7}$-campestanol & $0.66 \pm 0.09$ \\
\hline$\Delta^{7}$-avenasterol & $0.53 \pm 0.10$ \\
\hline Stigmastanol & $0.49 \pm 0.07$ \\
\hline 28-isoavenasterol & $0.30 \pm 0.01$ \\
\hline Cholesterol & $0.10 \pm 0.01$ \\
\hline & $0.07 \pm 0.001$ \\
\hline Brassicasterol & \\
\hline
\end{tabular}

Values are mean $\pm \mathrm{SD}$ for M. oleifera oil, analyzed individually in triplicate.

Table 5 shows the fatty acids composition in M. oleifera oil. This oil was found to contain a high level of oleic acid (65.00\%), palmitic acid $(12.31 \%)$ and linoleic acid $(16.00 \%)$, palmitoleic acid $(2.10 \%)$ and stearic acid $(5.10 \%)$, respectively. The content of principle fatty acid, i.e. oleic acid was well in line with that reported for M. oleifera oil from Kenya ${ }^{21}$ and India. ${ }^{20}$ High oleic acid in Moringa oil makes it desirable in the term of nutrition and high stability cooking and frying. ${ }^{3}$ The unsaturated fatty acids are very important for the stability of oils because of the chemical reactions occurring at the double bonds. The rate of those oxidation reactions depend on the number of double bonds in the carbon chain. Therefore, M. oleifera oil with high proportion of oleic acid is more stable than the others. In addition, oleic is less susceptible to oxidation than polyunsaturated fatty acid from the linoleic acid. Another interesting fact is that considerable content of linoleic acid as an essential fatty acid in the M. oleifera oil may be provide high nutritional remuneration and render beneficial healthy effect on blood lipid, blood pressure and cholesterol contents ${ }^{26}$ and it is preferred by industries when oil hydrogenation is required. 
Table 5 Fatty acid composition of Moringa oleifera oil

\begin{tabular}{ll}
\hline Fatty acids & M. oleifera oil \\
\hline CI6:0 & $12.31 \pm 1.88$ \\
CI6:I & $2.10 \pm 0.15$ \\
CI8:0 & $5.10 \pm 0.80$ \\
CI8:I & $65.00 \pm 5.13$ \\
CI8:2 & $16.00 \pm 2.10$ \\
$C I 8: 3$ & $0.30 \pm 0.01$
\end{tabular}

Values are mean $\pm \mathrm{SD}$ for M. oleifera oil, analyzed individually in triplicate.

Table 6 shows sera AST activity of rats fed on M. oleifera oil, olive oil and corn oil. They were slight non-significant increase in the activity of AST during the whole experiment for rats fed on $M$. oleifera seed oil, olive oil and corn oil. The data in Table 6 for rat sera activities of ALT and ALP on investigated oils indicate similar results for AST enzyme activity. Table 7 indicates the changes of total lipid contents of rats administered $M$. oleifera, olive and corn oils. The results demonstrate that the administration of oil (M. oleifera and olive) used gradual significant decrease in the levels of total lipids. On the contrary, the administration of corn oil caused significant increase in total lipid content of rat sera. ${ }^{27}$
Table 7 shows the sera total cholesterol contents of rats fed on $M$. oleifera, olive and corn oils. The results indicate very little increases (corn oil) and decreases (M. oleifera and olive oils). Changes in the levels of low-density lipoprotein cholesterol (LDL-C) of rats administered M. oleifera, olive and corn oils are shown in Table 7. The results indicate that there were very little changes in the LDL-C levels of rats fed on diets containing investigated oils.

Table 7 shows the changes in high-density lipoprotein cholesterol (HDL-C) levels of rats fed on diets containing M. oleifera, olive and corn oils. The results demonstrate that the above-mentioned oils possessed very little change on the levels of HDL-C.

Table 8 shows the changes of urea and uric acid contents of rats fed on M. oleifera, olive and corn oils. The results show that the administration of oils induced very little change on the sera levels of urea and uric acid during the whole experiment.

The results of the present study were demonstrated that most of the characteristics and quality attributes of M. oleifera oil from Saudi Arabia are quite identical with those of other Moringa oils reported in the literature. Its fatty acids composition revealed that it also fell in the category of high oleic oils just like other Moringa oils. Also, contains high considerable amount of tocopherol and phenolic compounds similar to that found in olive oil and could be utilized in diet as a source of vegetable oil human consumption.

Table 6 Influence of M. oleifera oil on the activity of serum AST, ALT, and AP (IU/L) of rats

\begin{tabular}{llll}
\hline Blood withdrawal period (week) & Corn oil & Olive oil & M. oleifera oil \\
\hline AST (IU/L) & & & \\
0 & $40.10 \pm 2.33$ & $40.10 \pm 2.33$ & $40.10 \pm 2.33$ \\
1 & $40.23 \pm 1.98$ & $40.63 \pm 2.54$ & $40.31 \pm 1.99$ \\
2 & $40.71 \pm 2.46$ & $40.61 \pm 2.78$ & $40.45 \pm 2.01$ \\
3 & $40.75 \pm 2.86$ & $40.60 \pm 2.60$ & $40.66 \pm 2.75$ \\
4 & $40.33 \pm 1.87$ & $40.76 \pm 2.98$ & $40.15 \pm 1.79$ \\
ALT (IU/L) & & & \\
0 & $44.00 \pm 3.11$ & $44.00 \pm 3.11$ & $44.00 \pm 3.11$ \\
1 & $44.15 \pm 3.23$ & $44.20 \pm 3.25$ & $44.16 \pm 3.56$ \\
2 & $44.80 \pm 3.81$ & $44.36 \pm 3.67$ & $44.40 \pm 3.39$ \\
3 & $44.85 \pm 3.80$ & $44.76 \pm 3.51$ & $44.81 \pm 3.78$ \\
4 & $44.46 \pm 3.25$ & $44.52 \pm 3.49$ & $44.64 \pm 3.54$ \\
AP (IU/L) & & & \\
0 & $79.00 \pm 6.77$ & $79.00 \pm 6.77$ & $79.00 \pm 6.77$ \\
1 & $79.31 \pm 6.54$ & $79.23 \pm 6.91$ & $79.19 \pm 6.86$ \\
2 & $79.43 \pm 6.31$ & $79.35 \pm 6.86$ & $79.39 \pm 6.97$ \\
3 & $79.67 \pm 6.87$ & $79.72 \pm 6.76$ & $79.86 \pm 6.78$ \\
4 & $79.80 \pm 6.90$ & $79.85 \pm 6.09$ & $79.81 \pm 6.18$ \\
\hline
\end{tabular}

Values are mean \pm SD for M. oleifera oil, analyzed individually in triplicate. 
Table 7 Influence of M. oleifera oil on sera total lipid, total cholesterol, LDL-cholesterol and HDL-cholesterol (mg/dl) of rats

\begin{tabular}{|c|c|c|c|}
\hline Blood withdrawal period (week) & Corn oil & Olive oil & M. oleifera oil \\
\hline \multicolumn{4}{|l|}{ Total lipids (mg/dl) } \\
\hline 0 & $280.00 \pm 10.67$ & $280.00 \pm 10.67$ & $280.00 \pm 10.67$ \\
\hline 1 & $280.50 \pm 10.81$ & $280.33 \pm 10.78$ & $280.51 \pm 10.88$ \\
\hline 2 & $280.70 \pm 10.80$ & $280.51 \pm 10.85$ & $280.60 \pm 10.94$ \\
\hline 3 & $280.81 \pm 10.66$ & $280.94 \pm 10.64$ & $280.85 \pm 10.62$ \\
\hline 4 & $280.90 \pm 10.93$ & $280.96 \pm 10.92$ & $280.90 \pm 10.23$ \\
\hline \multicolumn{4}{|l|}{ Total cholesterol (mg/dl) } \\
\hline 0 & $160.00 \pm 7.98$ & $160.00 \pm 7.98$ & $160.00 \pm 7.98$ \\
\hline 1 & $160.81 \pm 8.01$ & $160.85 \pm 8.16$ & $160.90 \pm 8.12$ \\
\hline 2 & $160.55 \pm 7.99$ & $160.70 \pm 8.45$ & $160.85 \pm 8.41$ \\
\hline 3 & $160.60 \pm 8.25$ & $160.65 \pm 7.56$ & $160.93 \pm 8.43$ \\
\hline 4 & $160.66 \pm 8.33$ & $160.80 \pm 8.09$ & $160.95 \pm 8.21$ \\
\hline \multicolumn{4}{|l|}{ LDL-cholesterol (mg/dl) } \\
\hline 0 & $59.50 \pm 4.11$ & $59.50 \pm 4.11$ & $59.50 \pm 4.11$ \\
\hline 1 & $59.80 \pm 4.58$ & $59.71 \pm 4.54$ & $59.69 \pm 4.25$ \\
\hline 2 & $59.85 \pm 4.63$ & $59.69 \pm 4.32$ & $59.72 \pm 4.36$ \\
\hline 3 & $59.90 \pm 4.28$ & $59.75 \pm 4.90$ & $59.81 \pm 4.77$ \\
\hline 4 & $60.11 \pm 4.19$ & $59.90 \pm 4.51$ & $59.85 \pm 4.58$ \\
\hline \multicolumn{4}{|l|}{ HDL-cholesterol (mg/dl) } \\
\hline 0 & $100.10 \pm 6.01$ & $100.10 \pm 6.01$ & $100.10 \pm 6.01$ \\
\hline 1 & $100.15 \pm 6.12$ & $100.20 \pm 6.58$ & $100.33 \pm 6.38$ \\
\hline 2 & $100.25 \pm 6.45$ & $100.35 \pm 6.42$ & $100.50 \pm 6.78$ \\
\hline 3 & $100.30 \pm 6.66$ & $100.45 \pm 6.23$ & $100.61 \pm 6.25$ \\
\hline 4 & $100.60 \pm 6.39$ & $100.50 \pm 6.89$ & $100.81 \pm 6.75$ \\
\hline
\end{tabular}

Values are mean \pm SD for M. oleifera oil, analyzed individually in triplicate. 
Table 8 Influence of M. oleifera oil on the sera urea and uric acid levels (mg/dl) of rats

\begin{tabular}{llll}
\hline Blood withdrawal period (week) & Corn oil & Olive oil & M. oleifera oil \\
\hline Urea $(\mathrm{mg} / \mathrm{dl})$ & & & \\
0 & $28.20 \pm 1.50$ & $28.20 \pm 1.50$ & $28.20 \pm 1.50$ \\
1 & $28.59 \pm 1.45$ & $28.61 \pm 1.84$ & $28.55 \pm 1.55$ \\
2 & $28.80 \pm 1.19$ & $28.66 \pm 1.49$ & $28.61 \pm 1.84$ \\
3 & $28.97 \pm 1.48$ & $28.74 \pm 1.78$ & $28.65 \pm 1.54$ \\
4 & $29.06 \pm 1.76$ & $28.92 \pm 1.92$ & $28.77 \pm 1.25$ \\
Uric acid (mg/dl) & & & \\
0 & $4.10 \pm 0.33$ & $4.10 \pm 0.33$ & $4.10 \pm 0.33$ \\
1 & $4.30 \pm 0.39$ & $4.51 \pm 0.53$ & $4.20 \pm 0.74$ \\
2 & $4.41 \pm 0.45$ & $4.55 \pm 0.57$ & $4.51 \pm 0.54$ \\
3 & $4.50 \pm 0.40$ & $4.60 \pm 0.65$ & $4.76 \pm 0.38$ \\
4 & $4.66 \pm 0.56$ & $4.67 \pm 0.39$ & $4.81 \pm 0.85$ \\
\hline
\end{tabular}

Values are mean $\pm \mathrm{SD}$ for M. oleifera oil, analyzed individually in triplicate.

\section{Acknowledgements}

None.

\section{Conflict of interest}

The author declares no conflict of interest.

\section{References}

1. Morton J. The horseradish tree, Moringa pterygosperma (Moringaceae)- A bon to arid lands? Economy Biotechnology. 1991;45(3):318-333.

2. Somali M, Bajneid M, Al-Fhaimani S. Chemical composition and characteristics of Moringa Peregrina seeds and sees oil. Journal American Oil Chemical Society. 1984;61(1):85-86.

3. Abdulkarim S, Long K, Lai O, et al. Some physical-chemical properties of Moringa oleifera seed oil extracted using solvent and aqueous enzymatic methods. Food Chemistry. 2005;93(2):253-263.

4. Anwar F, Bhanger M, Kazi T. Relationship between Rancimat and active oxygen method values at varying temperatures for several oils and fats. Journal of the American Oil Chemical Society. 2003;80(2):151-155.

5. Rahman I, Baruo S, Begum Z, et al. Physico-chemical properties of Moringa oleifera Lam. Seed oil of the indigenous cultivar. Journal Food Lipids. 2009;16(4):540-553.

6. Sreelatha S, Jeyachitra A, Padma P. Antiproliferation and induction of apoptosis by Moringa oleifera leaf extract on human cancer cells. Food Chemistry. 2011;49(6):1270-1275

7. Anwar F, Latif S, Ashraf M, et al. Moringa oleifera: A plant with multiple medicinal uses. Phytotheraphy Research. 2007;21(1):17-25.

8. Banerji R, Bajpai A, Verma SC. Oil and fatty acid diversity on genetically variable clones of Moringa oleifera from India. J Oleo Sci. 2009;58(1):916.

9. Dietz M, Metzler R, Zarate C. Food Security in the village: the case of oilseed processing. Appropriate Technology. 1994;20:9-11.
10. Anwar F, Ashraf M, Bhanger M. Interprovenance variation in the composition of Moringa oleifera from Pakistan. Journal of the American Oil Chemical Society. 2005;82(1):45-51.

11. Anwar F, Zafar S, Rashid U. Characterization of Moringa oleifera seed oil from drought and irrigated regions of Punjab, Pakistan. GrasasAceities. 2006;57(2):160-168.

12. Silva F, Matos J. Sobre disperses de Moringa oleifera paratratmento de ague. Technology Fortaleza. 2008;29:157-163.

13. Fahey J. Moringa oleifera: A Review of the medical evidence for its nutritional, therapeutic, and prophylactic. Part 1. Trees for life Journal. 2005;1:5.

14. Tsaknis JM Lalas S, Gergis V, Doutoglou V, et al. A total characterization of Moringa oleifera Malawi seed oil. La RivistaItalianan Sostanza Grasse. 1998;75:21-27.

15. Official methods of analysis of AOAC International, Association of Official Analytical Chemists. 19th ed. Washington, DC, USA: AOAC; 2012.

16. Farhoosh R. The effect of operational parameters of the Rancimat method on the determination of the oxidation stability measures and shelf-life prediction of soybean oil. Journal of the American Oil Chemists Society. 2007;84(3):205-209

17. Gutfinger T. Polyphenols in olive oils. Journal of the American Oil Chemists Society. 1981;58(1):966-968

18. $\mathrm{Xu} \mathrm{Z}$. Analysis of tocopherol and tocotrienols. In: RE Wrolstad Current Protocols in Food Analytical Chemistry. New York, USA: John Wiely and Sons, Inc; 2002. p. D1.5.1-d1.5.12.

19. Ogunsina BS, Indira TN, Bhatnahar AS, et al. Quality characteristics and stability of Moringa oleifera seed oil of Indian origin. J Food Sci Technol. 2011;51(3):503-510.

20. Lalas S, Tsaknis J. Characterization of Moringa oleifera seed oil variety periyakulam-1. Journal Food Composition and Analytical. 2002;15(1):6577.

21. Tsaknis J, Lalas S, Gergis V, et al. Characterization of Moringa oleifera seed oil of Kenya. J Agric Food Chem. 1999;47(11):4495-4499. 
22. Anwar F, Rashid U. Physical-chemical characteristics of Moringa oleifera and seed oil from a wild provenance of Pakistan. Pakistan Journal Biotechnology. 2007;39:1443-1453.

23. Osawa T. Novel Natural antioxidant for utilization in food and biological systems. In: I uritani, et al. editors. Postharvest Biochemistry of Plant Food-Materials in the Tropics. Tohyo, Japan: Japan Scientific Societies press; 1994.

24. Rossell JB. Vegetable oil and Fats. In: JB Rossell, et al. editors. Analysis of Oilseeds, Fats and Fatty Foods. New York, USA: Elsevier Applied Science; 1991. p. 261-239.
25. Tsaknis J. Characterization of Moringa Peregrina Arabia seed oil. Grasas Aceities. 1998;49(2):170-176.

26. Cheikh-Rouhou S, Besbes S, et al. Sterol Composition of Black cumin (Nigella sativa L.) and Aleppo pine (Pinus halepensis Mill.) seed oils. Journal Food Composition Analysis. 2008;21(2):162-168.

27. Masurekar S, Kadam V, Jadhav V. Roles of Moringa oleifera in medicine-A Review. Word Journal of Pharmacy \&Pharmaceutical Sciences. 2015;4:375-385. 